\title{
Implications of Organizational Culture, Servant Leadership, Competence on Quality of Work Life and Employee Performance Syar'i Garment
}

\author{
Maria Eliza1, Nimas Aryany Pratiwi² \\ 1,2Fakultas Ekonomi dan Bisnis Universitas Airlangga Surabaya \\ mria.eliza@gmail.com ${ }^{1}$, nimashalim@yahoo.com ${ }^{2}$
}

Received: 15 Januari 2021; Revised: 19 Januari 2021; Published: 30 June 2021

\begin{abstract}
ABSTRAK
Di Surabaya terdapat PT.X yang menjalankan usaha UKM garmen syar'i. Besarnya wilayah dan jumlah karyawannya menjadikan perusahaan ini harus memiliki upaya tertentu dalam menjalankan usahanya. Penelitian ini bertujuan untuk memberikan analisis pengaruh Budaya Organisasi, Servant Leadership dan Kompetensi Terhadap Quality of Work Life dan Kinerja Karyawan (Studi Kasus UKM Garmen Syar'i). Penelitian ini menggunakan pendekatan kuantitatif dengan Pengujian hipotesis penelitian dilakukan dengan pendekatan Structural Equation Model (SEM) berbasis Partial Least Square (PLS). hasil penelitian menjelaskan bahwa Budaya organisasi memilki pengaruh yang signifikan terhadap kualitas kehidupan kerja, Servant Leadership tidak memiliki pengaruh signifikan terhadap kualitas kehidupan kerja, kompetensi berpengaruh secara signifikan terhadap kualitas kehidupan kerja, budaya organisasi berpengaruh signifikan terhadap kinerja karyawan. Servant Leadership tidak berpengaruh terhadap kinerja karyawan, kompetensi berpengaruh signifikan terhadap kinerja karyawan dan Quality of work life berpengaruh signifikan terhadap kinerja karyawan.
\end{abstract}

Kata Kunci: Kompetensi; Quality Work of Life; kinerja karyawan.

\begin{abstract}
In Surabaya, there is PT. X, which runs a syar'i garment SME business. The size of the area and the number of employees make this company have certain efforts to run its business. This study analyzes the influence of Organizational Culture, Servant Leadership, and Competence on Quality of Work Life and Employee Performance (Case Study of Syar'i Garment SMEs). This study uses a quantitative approach. The research hypothesis testing is carried out using a Structural Equation Model (SEM) based on Partial Least Square (PLS). The study results explain that organizational culture has a significant influence on the quality of work-life. Servant Leadership has no significant effect on the quality of work life, competence has a significant effect on the quality of work life, and organizational culture has a considerable impact on employee performance. Servant Leadership does not affect employee performance, competence has a significant effect on employee performance, and quality of work-life significantly affects employee performance.
\end{abstract}

Key Word: Competence; Quality Work of Life; Employed Performance. 


\section{PENDAHULUAN}

Kehidupan organisasi tidak lepas dari budaya organisasi yang disesuaikan dengan kepemimpinan dalam organisasi itu sendiri. Menurut Schein (dalam Cotter-Lockard, et al. 2009) mengemukakan mengenai Budaya organisasi yaitu: "Budaya organisasi adalah pola asumsi dasar bersama yang telah dipelajari oleh suatu kelompok saat memecahkan masalah adaptasi eksternal dan integrasi internal, yang telah bekerja cukup baik untuk dianggap valid dan oleh karena itu, untuk diajarkan kepada anggota baru sebagai cara yang benar untuk mempersepsikan, berpikir, dan merasakan dalam kaitannya dengan hal tersebut".

Budaya organisasi merupakan pola asumsi yang umum digunakan untuk menyelesaikan masalah, menciptakan karyawan yang dapat beradaptasi dengan lingkungan dan merangkul anggota organisasi. Kotter \& Heskett (2011) dalam (Shahzad, 2012) memberikan analisa yang cukup jelas tentang bagaimana budaya organisasi secara positif atau negatif mempengaruhi kinerja ekonomi suatu organisasi. Peneliti dan manajemen praktisi melihat organisasi sebagai sesuatu dipengaruhi oleh variabel independen yang mempengaruhi sikap dan perilaku kerja karyawan (ODOR, 2018). Kehidupan organisasi yang dilihat dari budaya organisasi dapat dipisahkan dalam budaya organisasi yang kuat dan yang lemah (Robbins, et al. 2017).

Persaingan didunia bisnis yang semakin ketat memaksa perusahaan harus berinovasi agar dapat bersaing. Sumber daya manusia berperan strategis dalam mengantisipasi issue global pada dunia bisnis. Karyawan dengan tingkat pendidikan serta keahlian yang mumpuni serta manajemen perusahaan yang kooperatif, memberikan pengaruh yang signifikan terhadap pertumbuhan perusahaan secara berkelanjutan. Selaras dengan peningkatan intelligent dan dinamika perkembangan karyawan, kemampuan perusahaan untuk mengatur sumber daya manusia menjadi inti pembahasan dalam penelitian ini. Perusahaan yang mampu bersaing dapat dilihat melalui peningkatan kinerja perusahaan. Sedangkan peningkatan kinerja karyawan dapat dipengaruhi beberapa faktor yang terdapat pada budaya organisasi. Budaya organisasi menjadi faktor pendukung yang berkontribusi terhadap kinerja karyawan. Budaya organisasi kondusif akan berdampak positif bagi karyawan dalam meningkatkan kinerja. Standard Operation Procedure yang jelas, fasilitas dan gaji yang memadai sesuai dengan harapan karyawan atau gaji sesuai peraturan pemerintah akan memberikan kontribusi positif bagi karyawan. 
Servant Leadership juga memiliki pengaruh dalam kinerja karyawan. Servant Leadership adalah teori yang menyatakan bahwa pemimpin harus memberi pelayanan kepada sebuah organisasi, dan memiliki nilai seperti jujur, keberanian dan memperlakukan pegawai dengan baik. (Lussier \& Hendon 2019). Praktik Servant Leadership pada organisasi bertujuan meningkatkan performance karyawan, sesuai dengan penelitian sebelumnya bahwa Servant Leadership berpengaruh terhadap kinerja subordinate, hal dasar yang membedakan Servant Leadership dengan gaya kepemimpinan lain adalah, adanya prioritas untuk melayani sebelum keinginan untuk memimpin (Sendow and Tatilu 2014). Sebagaimana Allah telah berfirman:

"Dan rendahkanlah sayapmu (bertawadhu'lah) terhadap orang-orang yang beriman." (QS. Al-Hijr: 88)

Fathul menyampaikan bahwa di dalam Al-Quran terdapat tiga ayat yang menggunakan metafora "Rendahkanlah Sayapmu". Ayat tersebut terdapat pada Surat Asy-Syu'ara (26): 215, Surat Al-Hijr (17): 24, Surat Al-Isra (15): 88. Dari tiga ayat tersebut, dua di antaranya mengidikasikan bahwa pemimpin harus merendahkan sayap kepada pengikut kita (QS. 26:215 dan QS. 17: 24). Dua ayat pertama menarik untuk diulas karena Allah menyuruh kepada manusia untuk bertawadhu kepada pengikut seperti yang dicontohkan oleh para nabi dalam merendahkan sayapnya kepada para pengikutnya. Ini menjadi menarik ketika hal tersebut dikaitkan dengan perkembangan teori kepemimpinan yang disebut dengan servant leadership (kepemimpinan pelayan).

Kompetensi juga menjadi faktor yang mempengaruhi kinerja karyawan. Penerapan kompetensi yang tepat akan menumbuhkan semangat dan etos kerja bagi karyawan sehingga diharapkan kinerja karyawan meningkat. Kompetensi akan mendorong karyawan untuk bersaing secara sehat dalam meraih posisi menduduki posisi manajemen perusahaan. Oleh karena itu kompetensi yang benar - benar diterapkan pada perusahaan mampu melahirkan pemimpin yang handal dan mampu menjadi panutan bagi karyawan lainnya. Dampak positifnya adalah karyawan akan semakin berprestasi sehingga mudah dipromosikan ke posisi maupun jenjang karir yang lebih baik.

Perkembangan perusahaan dipengaruhi oleh kinerja karyawan yang optimal, kinerja merupakan perwujudan kerja yang dilakukan oleh karyawan yang biasanya dipakai sebagai dasar penilaian terhadap karyawan atau 
organisasi. Kinerja yang baik merupakan langkah untuk tercapainya tujuan perusahaan. Sehingga perlu diupayakan usaha untuk meningkatkan kinerja.

Dimana dijelaskan dalam ayat Al-Qur'an surat Al-ahqaaf ayat 19 "Dan setiap orang memperoleh tingkatan sesuai dengan apa yang telah mereka kerjakan dan agar Allah mencukupkan balasan amal perbuatan mereka dan mereka tidak dirugikan". Dalam ayat tersebut bahwasanya allah pasti akan membalas setiap amal perbuatan manusia berdasarkan apa yang telah mereka kerjakan. Artinya, jika seseorang melaksanakan pekerjaan dengan baik dan menunjukan kinerja yang baik pula bagi organisasinnya maka ia akan mendapat hasil yang baik pula dari kerjaannya dan akan memberikan keuntungan bagi organisasinya.

Selain kompetensi, Quality of Work Life disingkat (QWL) atau kualitas kehidupan kerja juga mempengaruhi kinerja karyawan. Quality of Work Life adalah situasi dimana karyawan sanggup untuk memenuhi kebutuhan dengan produktif bekerja dalam suatu organisasi atau perusahaan. (Gary, 2017). Definisi lain mengenai kualitas kehidupan kerja adalah suatu program yang efektif dalam memperbaiki kondisi kerja (dari sudut pandang karyawan) dan efektivitas organisasi yang lebih besar (dari sudut pandang manajer). Kualitas kehidupan kerja juga berperan dalam memantau karyawan tentang kualitas pekerjaan dan kualitas kehidupan kerja serta membantu manajer untuk mendapatkan ide perbaikan dalam suatu organisasi. (Parvar et. al, 2013).

Perkembangan dan dinamika lingkungan strategis serta tingginya kompetensi antara perusahaan membuat beberapa perusahaan harus berpikir keras bagaimana membangun dan mengembangkan perusahaan dari ancaman pamdemi saat ini. Disatu sisi, faktor internal perusahaan tersebut juga mempunyai sisi yang perlu diidentifikasi guna menjada sustainaibilitas sebuah perusahaan. Di Surabaya terdapat PT.X yang menjalankan usaha UKM garmen syar'I, memiliki faktor internal didalamnya yang terdapat budaya organisasi, servant leadership, kompetensi, quality fo work dan tentu kinerja karyawan. Guna menunjang keberlangsungan sebuah perusahaan, perlu dikaji apakah faktor internal tersebut memiliki pengaruh yang kuat.

Besarnya wilayah dan jumlah karyawannya menjadikan perusahaan ini harus memiliki upaya tertentu dalam menjalankan usahanya. Para pemimpin terdahulu perusahaaan ini kemudian membentuk visi, misi, dan tata nilai perusahaan, yang kemudian dijadikan budaya kerja untuk seluruh karyawan. Peneliti kemudian tertarik untuk melihat apakah terdapat hubungan antara budaya organisasi, servant leadership, dan kompetensi terhadap quality work of life dan kinerja karyawan dari UKM yang memproduksi garmen syar'i di Jawa Timur. Penelitian ini bertujuan untuk memberikan analisis pengaruh Budaya 
Organisasi, Servant Leadership dan Kompetensi Terhadap Quality of Work Life dan Kinerja Karyawan (Studi Kasus UKM Garmen Syar'i).

Penelitian ini menggunakan pendekatan kuantitatif dengan Pengujian hipotesis penelitian dilakukan dengan pendekatan Structural Equation Model (SEM) berbasis Partial Least Square (PLS). PLS adalah model persaman struktural (SEM) yang berbasis komponen atau varian. Structural Equation Modeling (SEM) merupakan teknik dengan kombinasi dari analisis jalur (path) dan analisis regresi yang memungkinkan peneliti menguji secara simultan rangkaian hubungan yang saling terkait antara variabel terukur (measured variables) dan konstrak laten (latent constructs) (Babin \& Anderson 2014). Penelitian ini diharapkan dapat memberikan konstribusi terhadap perusahaan garmen syar'i di PT. X dalam menjaga keberlangsungan perusahaan. Kedua, penelitian ini diharapkan dapat dijadikan referensi pada ilmu pengetahuan pengembangan organisasi dalam sebuah perusahaan pada umumnya.

Terdapat beberapa penelitian terdahulu antara lain pengaruh variabel motivasi kerja, kompetensi, lingkungan kerja, kompensasi terhadap Organizational Citizenship Behavior (OCB) dan kinerja petugas asuransi jiwa di Kota Batam (Suhardi, 2019). Penelitian analisis tentang sejauh mana kecerdasan emosional, employee engagement, dan servant leadership dapat memengaruhi kinerja pegawai (Al Amin et al, 2021). Penelitian tentang Pengaruh Servant Leadership, Self Awareness, dan Competence terhadap kinerja pegawai yang dimediasi oleh Komitmen Organisasi pada Dinas Pekerjaan Umum Pemerintah Kabupaten Bangkalan Indonesia (Hasanah \& Mujanah, 2020). Penelitian tentang pengaruh budaya organisasi, quality of work life dan kepemimpinan transformasional terhadap kinerja karyawan PT. Harum Indah Sari (HIS) Tours \& Travel Bali (Irmayanti \& Surya, 2020).

\section{METODE PENELITIAN}

Pendekatan yang digunakan adalah pendekatan kuantitatif. Jenis dan Sumber Data penelitian adalah melalui sumber data primer yang didapatkan melalui penyebaran kuesioner serta sumber data sekunder yang didapatkan melalui kajian telaah literatur, seperti jurnal, textbook, website, dan sumber pustaka lainnya yang masih memiliki relevansi dengan penelitian ini.

Populasi pada penelitian ini Populasi dalam penelitian ini adalah karyawan PT. X Surabaya dengan jumlah sampel ditetapkan sebanyak 112 
karyawan. Alasan penetapan kriteria tersebut karena sesuai dengan bidang organisasi yang diteliti. Serta kondisi lingkungan kerja PT X yang islami, bukan hanya sebagai industri penghasil garmen syariah, namun manajemen perusahaan juga menerapkan prinsip kerja syar'i.

Penentuan sampel dilakukan dengan menggunakan metode nonprobability sampling, yaitu dengan judgement sampling. Judgement sampling adalah bentuk sampling convenience yang didalamnya terdapat elemen populasi dipilih berdasarkan judgment peneliti. Ketentuan ukuran sampel 100 200 untuk teknik estimasi maximum likehood (ML), hal ini telah memenuhi kriteria jumlah minimal sampel. Analisis dalam penelitian ini dilakukan dengan dua tahap, yaitu tahap I adalah uji measurement model, yaitu menguji validitas dan reliabilitas konstruk dari masing-masing indikator dan tahap II adalah uji structural model yang bertujuan untuk mengetahui ada atau tidaknya pengaruh antar variabel/ korelasi antar konstruk yang diukur dengan menggunakan uji t dari PLS.

Penelitian ini menggunakan kuesioner untuk mengumpulkan data penelitian. Untuk mengetahui tingkat validitas dan reliabilitas dari kuesioner tersebut maka peneliti menggunakan program SPSS versi 23 dan AMOS 18. PLS merupakan metode analisis yang tidak berdasarkan pada jumlah asumsi. Oleh karena lebih fokus pada data dengan prosedur estimasi yang terbatas, maka misspesifikasi model tidak terlalu memiliki pengaruh terhadap estimasi parameter. PLS dapat menganalisis konstruk yang dibentuk secara bersamaan dengan indikator refleksif dan indikator formatif. Penggunaan PLS dalam penelitian ini dikarenakan terdapat beberapa variabel independen, maka dari itu untuk mengatasi hal tersebut harus digunakan metode analisis PLS. 


\section{HASIL PENELITIAN DAN PEMBAHASAN}

\section{Deskripsi Responden}

Tabel 1. Deskripsi Responden

\begin{tabular}{ccc}
\hline Jenis Kelamin & Frekuensi & Prosentase (\%) \\
\hline Lelaki & 42 & $37,5 \%$ \\
\hline Perempuan & 72 & $62,5 \%$ \\
\hline Total & 112 & $100 \%$ \\
\hline
\end{tabular}

Sesuai dengan data diatas, dapat disampaikan bahwa sampel penelitian dengan jenis kelamin perempuan sebanyak 70 orang atau sebesar $62,5 \%$ persen, sedangkan sampel penelitian dengan jenis kelamin laki - laki sebanyak 42 orang, atau sebesar $37,5 \%$. Sehingga mayoritas responden adalah jenis kelamin perempuan.

\section{Hasil Pengujian Goodness of Fit}

Suatu model dikatakan baik jika pengembangan hipotesis secara konseptual dan teoritis didukung oleh data empiris (Ahyar et al. 2020), hasil pengujian model persamaan struktural ditunjukkan pada gambar berikut:

\section{Gambar 2 Structural Equation Modeling}

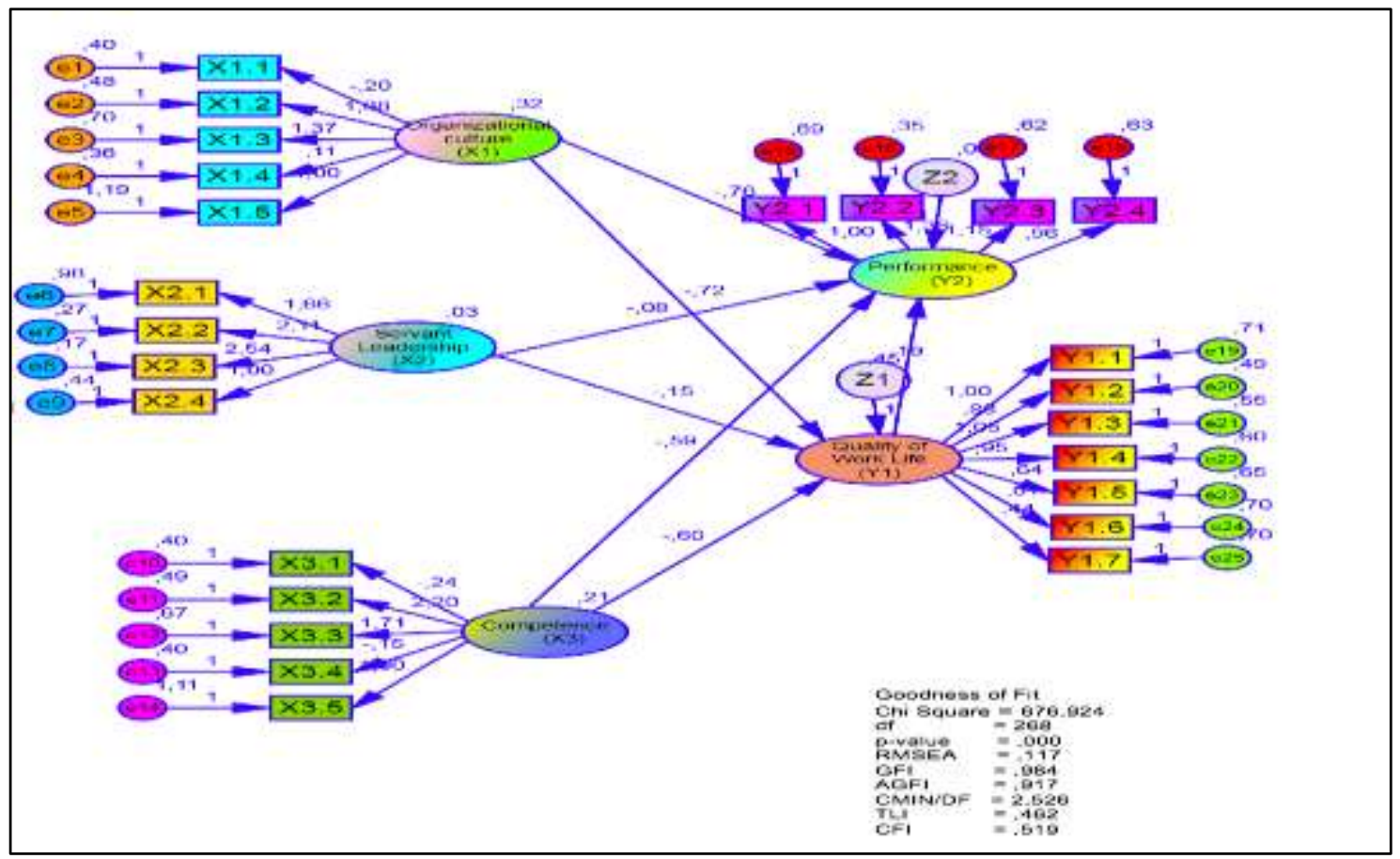


Tabel berikut merupakan pengujian Goodness of Fit, model yang diambil dari modifikasi terakhir atau hasil pengembangan model mod terbaik. Hasil analisis SEM model dari hasil pengujian lengkap beberapa Goodness of Fit longsleeved model sesuai tabel di bawah ini.

Tabel 2. Index of Suitability Model In Structural Models

\begin{tabular}{|l|c|c|c|}
\hline \multicolumn{1}{|c|}{ Goodness of Fit Measure } & Indeks & Cut off & Description \\
\hline Chi-square of estimate model & 676,924 & & No fit model \\
\hline Probability Level & 0,000 & $>0,05$ & No fit model \\
\hline Goodness of Index (GFI) & 0,984 & $\geq 0,9$ & Fit model \\
\hline Adjusted Goodness of Index (AGFI) & 0,917 & $\geq 0,9$ & Fit model \\
\hline RMSEA & 0,117 & $\leq 0,08$ & No fit model \\
\hline RMR & 0,041 & $\leq 0,05$ & Fit model \\
\hline Tucker-Lewis Index (TLI) & 0,462 & $\geq 0,9$ & No fit model \\
\hline Comparative Fit Index (CFI) & 0,519 & $\geq 0,9$ & No fit model \\
\hline
\end{tabular}

Sumber : Data diolah menggunakan aplikasi AMOS

Tabel tersebut menunjukkan Goodness of Fit Overall atau memenuhi kriteria fit suatu model. Dari hasil pengujian di atas dari delapan kriteria melalui analisis Structural Equation Modeling, menunjukkan terdapat 5 (lima) model yang menunjukkan kondisi sangat baik dan 3 (tiga) kriteria lainnya menunjukkan kondisi yang tidak menguntungkan. Sehingga model tersebut memenuhi unsur kelayakan desain model yang baik. Hasil tersebut menggambarkan desain studi penelitian sesuai menurut kriteria penelitian dan pengujian.

\section{Pengujian Hipotesis}

Fit model dilanjutkan dengan pengujian hipotesis untuk menguji hubungan kausalitas, apakah antara variabel endogen atau variabel eksogen mempengaruhi variabel endogen sesuai dengan hipotesis penelitian (Kline, 2015). Pengujian hipotesis dilakukan untuk mengetahui nilai koefisien setiap hubungan antar variabel. Nilai koefisien hubungan ini untuk menentukan arah hubungan positif atau negatif dan besarnya perubahan variabel endogen jika variabel eksogen berubah atau perubahan variabel endogen (dependen) jika variabel endogen (intervening) berubah (Akrout et al. 2016). Berikut hasil perhitungan hubungan pengaruh langsung dan tidak langsung antar variabel 
Tabel 3. Test Causality Regression Weight

\begin{tabular}{|c|c|c|c|c|c|c|}
\hline \multicolumn{2}{|c|}{ The Relationship of Causality } & \multirow{2}{*}{$\begin{array}{c}\begin{array}{c}\text { Std. } \\
\text { estima } \\
\text { te }\end{array} \\
-, 716\end{array}$} & \multirow{2}{*}{$\begin{array}{l}\text { SE } \\
206\end{array}$} & \multirow{2}{*}{$\begin{array}{c}\text { CR } \\
\begin{array}{c}\text { calcula } \\
\text { te }\end{array} \\
-3,473\end{array}$} & \multirow{2}{*}{$\begin{array}{l}\text { level } \\
\text { s of } \\
\text { Sig. } \\
* * *\end{array}$} & \multirow{2}{*}{$\begin{array}{c}\text { Descripti } \\
\text { on }\end{array}$} \\
\hline $\begin{array}{l}\text { Organizatio } \\
\text { nal culture } \\
\qquad\left(X_{1}\right)\end{array}$ & $\rightarrow \begin{array}{c}\text { Quality of work } \\
\left.\text { life_( } \mathrm{Y}_{1}\right)\end{array}$ & & & & & \\
\hline $\begin{array}{c}\text { Servant } \\
\text { Leadership } \\
\left(X_{2}\right)\end{array}$ & $\rightarrow \begin{array}{c}\text { Quality of work } \\
\left.\text { life_( } \mathrm{Y}_{1}\right)\end{array}$ &,- 150 & 470 &,- 319 & 750 & $\begin{array}{c}\text { No } \\
\text { significan } \\
t\end{array}$ \\
\hline $\begin{array}{l}\text { Competence } \\
\qquad\left(\mathrm{X}_{3}\right)\end{array}$ & $\rightarrow \begin{array}{c}\text { Quality of work } \\
\left.\text { life_( } \mathrm{Y}_{1}\right)\end{array}$ &,- 597 & 221 & $-2,695$ & ,007 & $\begin{array}{c}\text { significan } \\
t\end{array}$ \\
\hline $\begin{array}{l}\text { Organizatio } \\
\text { nal culture } \\
\qquad\left(\mathrm{X}_{1}\right)\end{array}$ & $\begin{array}{l}\text { Performance } \\
\qquad\left(\mathrm{Y}_{2}\right)\end{array}$ &,- 756 & 286 & $-2,648$ & ,008 & $\begin{array}{c}\text { significan } \\
\mathrm{t}\end{array}$ \\
\hline $\begin{array}{c}\text { Servant } \\
\text { Leadership } \\
\left(\mathrm{X}_{2}\right)\end{array}$ & $\begin{array}{l}\text { Performance } \\
\qquad\left(\mathrm{Y}_{2}\right)\end{array}$ &,- 076 & 388 & -,197 & ,844 & $\begin{array}{c}\text { No } \\
\text { significan } \\
t\end{array}$ \\
\hline $\begin{array}{c}\text { Competence } \\
\qquad\left(X_{3}\right)\end{array}$ & $\rightarrow \quad \begin{array}{c}\text { Performance } \\
\left(\mathrm{Y}_{2}\right)\end{array}$ &,- 591 & 261 & $-2,264$ & ,024 & $\begin{array}{c}\text { significan } \\
\mathrm{t}\end{array}$ \\
\hline $\begin{array}{c}\text { Quality of } \\
\text { work life }\left(\mathrm{Y}_{1}\right)\end{array}$ & $\rightarrow \quad \begin{array}{c}\text { Performance } \\
\left(\mathrm{Y}_{2}\right)\end{array}$ &,- 448 & 219 & $-2,046$ & ,041 & $\begin{array}{c}\text { significan } \\
t\end{array}$ \\
\hline
\end{tabular}

Estimasi parameter untuk variabel budaya organisasi terhadap motivasi kerja sesuai indikator menunjukkan hasil signifikan dengan nilai CR -3.473, lebih besar dari 1,96. Selain itu diperoleh tingkat signifikansi $0,000(p<0,05)$. Sehingga disimpulkan variabel budaya organisasi memiliki pengaruh signifikan terhadap kualitas kehidupan kerja. Sesuai dengan penelitian sebelumnya bahwa kualitas kehidupan kerja sebagai dampak atas efektivitas organisasi serta kombinasi atas partisipasi anggota organisasi dalam pemecahan suatu masalah maupun dalam 
decision making. Karyawan yang memiliki partisipasi, pemberdayaan dan komitmen yang tinggi akan menghasilkan kualitas kehidupan kerja yang baik (Luthans 2012).

Estimasi parameter untuk variabel servant leadership terhadap kompetensi berdasarkan indikator menunjukkan hasil signifikan dengan CR -0,319, lebih kecil dari 1,96 dan taraf signifikansi 0,750 ( $p>0,05)$. Sehingga Servant Leadership berpengaruh signifikan terhadap kualitas kehidupan kerja. Hal ini sesuai dengan penelitian sebelumnya menyimpulkan servant leadership berpengaruh signifikan terhadap kualitas kehidupan kerja (Parvar et. al, 2013) penelitian tersebut juga mengonfirmasi teori tentang servant leadership (Greenleaf, 2019) serta teori penelitian kualitas kehidupan kerja (Sirgy \& Lee 2018).

Hasil estimasi parameter untuk variabel kompetensi terhadap kualitas kehidupan kerja sesuai indikator menunjukkan hasil signifikan dengan nilai CR -2.695, lebih besar dari 1,96 dan taraf signifikansi 0,007 ( $p<0,05)$. Sehingga menyatakan kompetensi memiliki pengaruh signifikan terhadap kualitas kehidupan kerja. Pendapat sebelumnya bahwa kompetensi adalah hal sulit untuk ditiru, dikarenakan karakteristik yang berbeda serta spesifik untuk setiap individu. Sesuai pendapat tersebut, dengan persaingan yang ketat saat ini, kompetensi menjadi modal utama perusahaan untuk membangun dan mencapai competitive advantage secara berkelanjutan (Winanti, 2011).

Hasil estimasi parameter untuk variabel kualitas kehidupan kerja terhadap kinerja pegawai berdasarkan indikator menunjukkan hasil signifikan dengan CR -2,046, lebih besar dari 1,96 dan taraf signifikansi 0,041 ( $\mathrm{p}<0,05$ ). Menyatakan kualitas kehidupan kerja berpengaruh signifikan terhadap kinerja karyawan. Penelitian sebelumnya menyimpulkan bahwa kehidupan kerja berpengaruh signifikan terhadap kinerja karyawan, bahwa konsep kualitas kehidupan kerja menunjukkan esensi rasa hormat individu dilingkungan kerja. Peran penting kualitas kehidupan kerja dengan mengubah situasi kerja dalam organisasi secara teknis untuk mengarah pada kinerja lebih baik (Mendis \& Weerakkody 2018).

Estimasi parameter untuk variabel budaya organisasi terhadap kinerja pegawai sesuai indikator menunjukkan hasil yang signifikan dengan CR -2,468, lebih besar dari 1,96 dan tingkat signifikansi 0,008 ( $p<0,05)$. Budaya organisasi berpengaruh signifikan terhadap kinerja karyawan. Teori sebelumnya menyatakan budaya organisasi sebagai variabel intervening. Karyawan dari keseluruhan persepsi subjektif sehingga budaya organisasi mempengaruhi kepuasan dan kinerja karyawan. Adanya budaya organisasi yang kuat akan membuat karyawan menjadi lebih berkarakter sehingga karyawan akan lebih 
percaya diri dalam mengemban tugas dan meningkatkan performa. (Robbins et. al, 2017).

Estimasi parameter untuk variabel kompetensi terhadap kinerja pegawai sesuai indikator menunjukkan hasil yang tidak signifikan dengan nilai CR sebesar 2,264, lebih besar dari 1,96 dan taraf signifikansi 0,024 ( $p<0,05)$. Sehingga Kompetensi berpengaruh signifikan terhadap kinerja karyawan. Hal ini didukung oleh penelitian sebelumnya bahwa kompetensi berpengaruh signifikan terhadap kinerja karyawan. Kompetensi pada setiap individu berbeda - beda dan tidak mudah untuk ditiru, sehingga karyawan dapat memaksimalkan kompetensi secara spesifik untuk mendukung kinerja pada perusahaan ( $\mathrm{Xu} \& \mathrm{Ye}$ 2014).

Estimasi parameter untuk variabel servant leadership terhadap kinerja pegawai berdasarkan indikator menunjukkan hasil signifikan dengan CR -0,197, lebih kecil dari 1,96 dan tingkat signifikansi 0,844 ( $p>0,05)$. Servant leadership tidak berpengaruh signifikan terhadap kinerja karyawan. Hasil penelitian ini mendukung penelitian sebelumnya, bahwa servant leadership memiliki dampak signifikan terhadap kinerja, serta berkewajiban untuk peduli terhadap anggota tim kerja, sehingga tim kerja merasa penting dan dibutuhkan dalam kelangsungan organisasi (Setyaningrum et. al, 2017).

Kepemimpinan adalah kemampuan seseorang dalam memengaruhi orang lain yang umumnya melalui motivasi untuk bekerja sesuai dengan tujuan dan sasaran yang berlaku. Sebagai manajer sudah umum diketahui bahwa gaya kepemimpinan yang dilakukan akan sangat mempengaruhi bagaimana perilaku karyawan tersebut bekerja untuk sampai menuju goals atau tujuan-tujuan yang sudah manajer buat.

Selain mempengaruhi bagaimana perilaku karyawan tersebut, pimpinan harus menguasai hal-hal seperti manajemen yang biasa dibutuhkan untuk mengatasi kerumitan dengan cara membuat tata tertib dengan menyusun rencana-rencana formal, merancang struktur organisasi yang ketat, setelah itu memantau hasil yang sudah dilakukan dengan cara membandingkannya dengan rencana yang telah ditetapkan sebelumnya.

Seperti yang ditulis oleh (Greenleaf, 2019), servant leadership ini dapat hadir dari seseorang yang mempunyai rasa alami ingin melayani kemudian secara sadar membawa seseorang untuk memimpin dengan cara menempatkan kebutuhan karyawan sebagai prioritas, mengenal kehormatan dan pentingnnya nilai bagi setiap individu, dan membatu orang lain dalam mencapai suatu tujuan bersama. Karakteristik utama yang membedakan antara kepemimpinan pelayan 
dengan model kepemimpinan lainnya dalah keinginan untuk melayani hadir sebelum adanya keinginan untuk memimpin. Selanjutnya mereka yang memiliki kualitas kepemimpinan akan menjadi pemimpin.

Sedangkan prioritas kepemimpinan pelayan yang pertama dan utama adalah pada pengembangan karyawan yang menghasilkan nilai tambah bagi pelanggan, lalu terciptanya kepuasan pelanggan yang diikuti dengan keberhasilan yang berkesinambungan. Apabila kepemimpinan masih otoriter dan hanya mementingkan keuntungan diri sendiri maka sudah dipastikan yang sejahtera hanya pemimpinnya saja.

Kesimpulannya, gaya kepemimpinan servant leadership akan selalu mengoptimalan pemberdayaan dan pengembangan anggota organisasinya dan melayani orang lain melebihi rasa mementingkan dirinya sendiri.

Karakteristik utama yang membedakan antara kepemimpinan pelayan dengan model kepemimpinan lainnya adalah keinginan untuk melayani hadir sebelum adanya keinginan untuk memimpin. Selanjutnya mereka yang memiliki kualitas kepemimpinan akan menjadi pemimpin. Sedangkan prioritas kepemimpinan pelayan yang pertama dan utama adalah pada pengembangan bawahan yang menghasilkan nilai tambah bagi pelanggan, lalu terciptanya kepuasan pelanggan yang diikuti dengan keberhasilan yang berkesinambungan.

\section{KESIMPULAN}

Analisis pengaruh Budaya Organisasi, Servant Leadership dan Kompetensi Terhadap Quality of Work Life dan Kinerja Karyawan (Studi Kasus UKM Garmen Syar'i) berdasarkan hasil penelitian menjelaskan bahwa kompetensi memiliki pengaruh signifikan terhadap kualitas kehidupan kerja. Servant Leadership berpengaruh signifikan terhadap kualitas kehidupan kerja. Kualitas kehidupan kerja berpengaruh signifikan terhadap kinerja karyawan. Estimasi parameter untuk variabel budaya organisasi terhadap kinerja pegawai menyatakan bahwa budaya organisasi berpengaruh signifikan terhadap kinerja karyawan. Selanjutnya, Kompetensi berpengaruh signifikan terhadap kinerja karyawan. Estimasi parameter untuk variabel servant leadership terhadap kinerja menunjukkan bahwa Servant leadership tidak berpengaruh signifikan terhadap kinerja karyawan 
Maria Eliza: Competence; Quality Work of Life; Employed Performance

\section{DAFTAR PUSTAKA}

Ahyar, Hardani et al. 2020. Buku Metode Penelitian Kualitatif E Kuantitatif.

Akcam, Bahadir K., Senem Guney, and Anthony M. Cresswell. 2019. “Research Design and Major Issues in Developing Dynamic Theories by Secondary Analysis of Qualitative Data." Systems 7(3): 40.

Akrout, Houcine, Mbaye Fall Diallo, Wafa Akrout, and Jean Louis Chandon. 2016. "Affective Trust in Buyer-Seller Relationships: A Two-Dimensional Scale." Journal of Business and Industrial Marketing 31(2): 260-73.

Al Amin, Ahmad Firman, Anshar Daud, "Engagement, Employee et al. 2021. "Employee Engagement Dan Kinerja Pegawai, Suatu Analisis Mediasi Dengan Antecedent Kecerdasan Emosional Dan Servant Leadership." 2: $10-23$

Babin, Barry J, and Rolph E Anderson. 2014. On Multivariate Data Analysis Joseph F. Hair Jr. William C. Black Seventh Edition.

Cooper, Donald R., and Pamela S. Schindler. 2014. Business Research Methods Business Research Methods 12th Edition.

Cotter-Lockard, Dorianne, Charles Seashore, and Jerry Snow. 2009. "Edgar Schein's Organizational Culture and Leadership, As Seen Through the Lens of Ken Wilber's AQAL Framework (and The Author's Eyes)." Fielding Graduate University 10(July): 1-35.

Gary, Dessler. 2017. Pearson Education Human Resource Management Fifteenth Edition.

Greenleaf, Robert K. 2019. “The Servant as Leader.” In Leadership,.

Haryono, Siswoyo. 2017. "Metode SEM Untuk Penelitian Manajemen Dengan AMOS 22.00, LISREL 8.80 Dan Smart PLS 3.0." Luxima Metro Media: 450.

Kline, R B. 2015. Methodology in the social sciences TXTBK Principles and Practices of Structural Equation Modelling Ed. $4^{* * *}$.

Lussier, Robert N., and John R. Hendon. 2019. Sage Publications Ltd. Human Resource Management - Functions, Applications, and Skill Development. 
Luthans, Fred. 2012. Organizational behavior: an edivence-based approach Organizational Behavior an Evidence-Based Approach 12th Edition.

Mendis, M. D. V. S., and W. A. S. Weerakkody. 2018. “The Impact of Work Life Balance on Employee Performance with Reference to Telecommunication Industry in Sri Lanka: A Mediation Model." Kelaniya Journal of Human Resource Management.

Ni Putu Pratiwi Irmayanti dan Ida Bagus Ketut Surya, Pengaruh Budaya Organisasi, Quality Of Work Life dan Kepemimpinan Transformasional Terhadap Kinerja Karyawan. Manajemen, E-jurnal. 2020. “9(4): 1572-93

Odiakaose ODOR, Hillary. 2018. "Organisational Culture and Dynamics." International Journal of Scientific Research and Management 6(01).

Parvar, Mohammad Reza Faghih, Sayyed Mohsen Allameh, and Reza Ansari. 2013. “Effect of Quality of Work Life on Organizational Commitment by SEM (Case Study: OICO Company)." International Journal of Academic Research in Business and Social Sciences.

Robbins, Stephen P, Timothy A Judge, and Timothy T Campbell. 2017. Pearson Organizational Behavior: Second Edition.

Sendow, Greis, and James Tatilu. 2014. "Kepemimpinan Transaksional, Transformasional, Servant Leadership Pengaruhnya Terhadap Kinerja Karyawan Pada Pt. Sinar Galesong Pratama Manado." Jurnal Riset Ekonomi, Manajemen, Bisnis dan Akuntansi.

Setyaningrum, Retno Purwani, Margono Setiawan, and Surachman Surachman. 2017. "Organizational Commitments Are Mediation Of Relationships Between Servant Leadership And Employee Performance." Jurnal Aplikasi Manajemen.

Shahzad, Fakhar. 2012. "Impact of Organizational Culture on Organizational Performance : An Overview." Interdisciplinary Journal of Contemporary Research in Business 3(3): 975-85.

Sirgy, M. Joseph, and Dong Jin Lee. 2018. "Work-Life Balance: An Integrative Review." Applied Research in Quality of Life.

Suhardi, "Pengaruh Motivasi Kerja, Kompetensi, Lingkungan Kerja Dan Kompensasi Terhadap Kinerja Karyawan Asuransi Jiwa Di Kota Batam 
Maria Eliza: Competence; Quality Work of Life; Employed Performance

Dengan Organizational Citizenship Behavior Sebagai Variabel Intervening." Jurnal Benefita, 4(2).

Uswatun Hasanah dan Siti Mujanah, "The Effect Of Servant Leadership, SelfAwareness, and Competence on Organizational Commitment And Performance Of Employees Of Public Works In Bangkalan District “ 2020. 4(2020): 136-46

Winanti, Marliana Budhiningtias. 2011. “Pengaruh Kompetensi Terhadap Kinerja Karyawan (Survei Pada Pt. Frisian Flag Indonesia Wilayah Jawa Barat)." Majalah Ilmiah UNIKOM.

Xu, Anguo, and Long Ye. 2014. "Impacts of Teachers' Competency on Job Performance in Research Universities with Industry Characteristics: Taking Academic Atmosphere as Moderator." Journal of Industrial Engineering and Management. 